\title{
AKTIFITAS KEAGENAN DALAM MENANGANI DOKUMEN DAN KEBUTUHAN KAPAL PADA PT.GESURI LIOYD CABANG KUALA TANJUNG
}

\author{
${ }^{1}$ Yursal, ${ }^{2}$ Muhammad Sahid ${ }^{3}$ Ade Ria \\ ${ }^{1}$ TEKNIKA ${ }^{2,3}$ KPNK, Politeknik Adiguna Maritim Medan \\ email:yusal07@gmail.com
}

\begin{abstract}
Abstrak. Keagenan adalah merupakan salah satu usaha perusahaan pelayaran yang menangani dokumen-dokumen dan kebutuhan kapal, dari kapal yang akan masuk kedermaga sampai kapal selesai melakukan kegiatan bongkar/ muat di dermaga dan selanjutnya kapal akan berangkat kepelabuhan singgah selanjutnya. Pada PT. Gesuri Lloyd cabang Kuala Tanjung adalah perusahaan pelayaran yang menangani dokumen dan kebutuhan-kebutuhan kapal seperti pengurusan sertifikat kapal yang sedang lewat jangka waktunya, menyediakan supply air tawar, permintaan crew berobat, permintaan bahan makanan untuk crew dan lain sebagainya, dari mulai masuk hingga keluarnya kapal tersebut. Kapal yang biasa di tangani oleh perusahaan PT. Gesuri Lloyd cabang Kuala Tanjung ialah kapal Tanker, Kapal Tugboat, dan kapal Cargo. Dan di dermaga Kuala Tanjung bukan dermaga umum tetapi dermaga khusus dalam arti dermaga di Kuala Tanjung ialah darmaga yang untuk kepentingan sendiri dikarenakan satu perusahaan besar memiliki dermaganya sendiri. Dan pada PT. Gesuri Lloyd Cabang Kuala Tanjung bekerja sama dengan perusahaan bongkar muat yang atas nama PT. Duet Pratama Samudera dan PT. Kuala Jaya Samudera. Intansi-intansi yang terkait di Kuala Tanjung menjalinhubungan yang baik kepada perusahaan PT. Gesuri Lloyd cabang Kuala Tanjung, Dalam penulisan makalah ini metode yang diambil untuk mengumpulkan data yaitu dengan study lapangan (field research), metode perpustakaan (field library).
\end{abstract}

Kata Kunci: Keagenan, Dokumen,PT.Gesuri Lioyd Cabang Kuala Tanjung

\begin{abstract}
Agency is one of the shipping companies' businesses that handles the documents and needs of the ship, from the ship that will enter the dock until the ship has finished loading/unloading activities at the dock and then the ship will leave for the next port of call. At PT. Gesuri Lloyd Kuala Tanjung branch is a shipping company that handles documents and ship needs such as processing ship certificates that are overdue, providing fresh water supply, requests for medical treatment crews, requests for food for crew and so on, from entry to departure that. The ship which is usually handled by PT. Gesuri Lloyd's Kuala Tanjung branch are tankers, tugboats, and cargo ships. And at the Kuala Tanjung pier, it is not a public pier but a special pier in the sense that the pier at Kuala Tanjung is a pier for its own sake because one large company has its own pier. And at PT. Gesuri Lloyd Kuala Tanjung Branch in cooperation with a loading and unloading company on behalf of PT. Duet Pratama Samudera and PT. Kuala Jaya Ocean. Relevant agencies in Kuala Tanjung maintain good relations with the company PT. Gesuri Lloyd Kuala Tanjung branch, In writing this paper the method used to collect data is by field study (field research), library method (field library).
\end{abstract}




\section{PENDAHULUAN}

Pelayaran atau angkutan laut merupakan bagian dari transportasi yang tidak dapat dipisahkan dengan bagian dari sarana tranportasi lainnya dengan kemam-puan untuk menghadapi perubahan kedepan, mempunyai karakteristik karena mampu melakukan pengangkutan secara massal. Dapat menghubungkan dan menjangkau wilayah satu dengan yang lainnya melalui perairan, sehingga mempunyai potensi yang kuat untuk dikembangkan dan peranannya baik nasional maupun internasional sehingga mampu mendorong dan menunjang pem-bangunan pembangunan nasional demi maningkatkan kesejahteraan masyara-kat.

Dalam menyongsong perdagangan bebas yang semakin pesat maka perus-ahaan pelayaran dituntut untuk dapat menyediakan kapal untuk angkutan antar pulau sehingga kelancaran arus barang dipelabuhan dapat berjalan dengan efek-tif dan efisien. Untuk terlaksananya kegiatan-kegiatan suatu perusahaan pe-layaran dipelabuhan dapat berjalan dengan efektif dan efisien tidak terlepas dari kerjasama dan dukungan instansi pemerintah.

Instansi pemerintah yang melaksanakan peraturan perundang-undangan dalam kegiatan dipelabuhan antara lain Syahbandar, Bea dan Cukai, Karantina kesehatan pelabuhan dan kantor Imigrasi. Untuk pelayanan kapal yang masuk dan keluar dari pelabuhan harus dilakukan oleh instansi-instansi tersebut.

Namun demikian sistem keselamatan dan keamanan menjadi faktor pent-ing yang harus diperhatikan dan sebagai dasar dan tolak ukur bagi

pengambilan keputusan dalam menentukan kelayakan dalam pelayaran baik dilihat dari sisi sarana berupa kapal maupun prasarana seperti sistem navigasi maupun sumber daya manusia yang terlibat di dalamnya.

Banyak contoh kasus terjadinya kecelakaan laut yang disebabkan dilang-garnya standar keamanan yang telah di tetapkan. Adapun instansi menangani keselamatan di bidang pelayaran yaitu Direktorat Keselamatan Penjagaan Laut Pantai atau biasa disingkat KPLP Direktorat Jenderal Perhubungan Laut.

Namun jika peraturan yang sudah di buat sedemikian rupa akan tetapi tidak didukung dengan pelayanan yang prima oleh petugas/instansi terkait di-pelabuhan juga akan berdampak terhambat atau terkendala kegiatan kapal di-pelabuhan.

Berbagai masalah tentang pelayaran menjadi latar belakang penulis untuk melakukan penelitian dan permasalahan kebijakan tentang keselamatan dan keamanan pelayaran sebagai lembaga pelayanan publik, tentunya kualitas pela-yanan kepada pihakpihak terkait khususnya pelayanan dibidang kepelabuhanan sangat berpengaruh terhadap Keselamatan Pelayaran. Pelayaran dibidang Kepelabuhanan menjadi salah satu hal yang menarik untuk dibahas dan dilakukan kajian oleh karena faktor kepentingan keselamatan pelayaran.

\section{METODE PENELITIAN}

Dalam menyusun tulisan ini tentunya membutuhkan bahan-bahan dan fakta yang dapat mendukung penulis sehingga dimengerti oleh pembaca.Dalam menyusun tulisan ini digunakan metode pengumpulan data sebagai berikut :

1.Metode Observasi Lapangan (Field Reseach)

Observasi merupakan suatu metode penelitian langsung dilapangan guna memperoleh data yang akurat yang diperlukan sesuai dengan maksud dan tujuan dari makalah ini.

2. Metode Keperpustakaan (Library Research)

Studi Keperpustakaan dilakukan dengan mencari atau mencatat buku-buku yang ada diperpustakaan mengenai materi yang dibahas oleh penulis.

\section{HASIL DAN PEMBAHASAN}

\section{A.Sejarah Singkat Perusahaan}

\section{Sejarah singkat PT. Gesuri Lloyd Cabang Kuala Tanjung}

Perusahaan pelayaran PT. Gesuri Lloyd Cabang Kuala Tanjung resmi didirikan pada tahun 1964 di Jl. Pelabuhan PT. Inalum Desa Kuala Tanjung Kecamatan Sei Suka, Kabupaten Batu Bara.

Perusahaan pelayaran PT. Gesuri Lloyd Cabang Kuala Tanjung bekerja sama dengan Perusahaan Bongkar Muat (PBM) PT. Duet Pratama Samudera dan PT. Kuala Jaya Samudera untuk proses bongkar muat dari kapal kelapan-gan penumpukan dan dari gudang ke atas kapal.

Pusat dari PT. Gesuri Lloyd terletak di Jl. Tiang Bendera IV No. 45 Jakarta Barat-11230. 
Penulis memperhatikan bahwa aktifitas pada perusahaan tempat penu-lis praktek terdiri dari beberapa aktifitas yaitu :

a.PT. Gesuri Lloyd Cabang Kuala Tanjung sebagai Perusahaan Pelayaran yang bergerak dibidang keagenan saja, perusahaan ini ditunjuk oleh Own-er's atau pemilik kapal untuk mengageni kapal lokal maupun kapal asing, Kapal yang biasa diageni oleh PT. Gesuri Lloyd cabang Kuala Tanjung adalah kapal cargo, kapal tanker dan kapal tugboat/ tongkang.

b.PT. Gesuri Lloyd Cabang kuala Tanjung sebagai Perusahaan Pelayaran yang melayani seluruh kebutuhan kapal seperti Bunker (Penyediaan

c.Minyak) Fresh water, membawa crew kapal berobat jika ada yang sakit dan kebutuhan-kebutuhan lainnya.

\section{B. Aktifitas Perusahaan PT. Gesuri Lloyd Cabanag Kuala Tanjung.}

\section{Aktivitas Pelayanan Kapal}

\section{a.Sebelum Kapal Tiba (Clearance In)}

Sebelum kedatangan kapal pihak perusahaan pelayaran atau agen telah menerima Rencana Kedatangan Kapal (RKK) dan pemilik kapal atau kantor pusat melalui telepon atau email.

Berdasarkan rencana tersebut maka dipersiapkan segala sesuatu yang diperlukan untuk pengurusan Clearance in kapal agar kapal dapat sandar dan melakukan bongkar muat dan berlayar dengan aman.

Kegiatan penanganan terhadap kapal merupakan kegiatan perencanaan dan pelaksanaan penambatan kapal yang disesuaikan an-tara lokasi tambat dengan jenis tipe kapal.

Sebelum kapal tiba dipelabuhan tujuan ship owner`s/ prin-cipal akan memberitahukan kantor cabang atau agen yang telah di-tunjuk melalui letter of oppointment bahwa kapal akan mengunjungi pelabuhan Kuala Tanjung. Sebelum kapal memasuki pelabuhan Kuala Tanjung untuk kedatangan kapal pihak pemilik kapal mengirimkan dokumendokumen yang biasanya dikirim melalui email. Dimana isi dari dokumen email tersebut memberitahukan tentang hal-hal berikut ini :

1) Surat penunjukan keagenan dari pemilik kapal /owner's.

2) Nama Kapal

3) Ukuran Kapal (GRT/DWT)
4) Bendera / IMO number

5) Pelabuhan Singgah

6) ETA/ETD

7) Jumlah muatan yang akan dimuat atau dibongkar

8) Pelabuhan asal/tujuan

9) Crew List/ kebangsaan

10) Status Kapal

Cabang atau agen dapat menerima pemberitahuan akan ked-atangan kapal melalui radio telegram, radio pantai, atau telepon. Setelah cabang atau agen menerima pemberitahuan tersebut maka principal akan mengirim beberapa dokumen kapal kepada cabang atau agen yang di pelabuhan tujuan.

Dokumen - dokumen tersebut antara lain sebagai berikut :

a). Ship Particular

yaitu dokumen yang menerangkan tentang nama kapal, ukuran kapal, kebangsaan dan lain sebagainya.

b).Crew List yaitu daftar anak buah kapal.

c).International Tonnage Certificate yaitu dokumen yang men-erangkan tentang ukuran kapal.

d).Cargo Manifest yaitu dokumen yang menerangkan tentang daftar muatan yang diangkut oleh kapal.

e).Last Port Clearance yaitu surat persetujuan berlayar terakhir.

\section{b.Setelah Kapal Tiba}

Dalam kegiatan pelayanan kapal setelah kapal tiba perus-ahaan/ agen mengurus tanggung jawab atas kebutuhan kapal termasuk pelayanan dokumen, kebutuhan kapal dan crew maupun kegiatan saat kapal akan sandar untuk melakukan kegiatan bongkar/ muat sampai kapal meninggalkan pelabuhan Kuala Tanjung.

\section{c.Setelah Kapal Sandar}

Setelah kapal sandar perusahaan pelayaran/ agen mengambil dokumen kapal, beserta dokumendokumen untuk di memorandum dan proses clearance in dan clearance out. Dan mengurus kegiatan bongkar/ muat, pelaksanaan bongkar muat 
dilaksanakan oleh perus-ahaan yang bergerak di bidang kegiatan bongkar muat barang dari ka-pal menuju gudang/ lapangan penumpukan atau dari gudang/ lapangan penumpukan ke kapal.

Dalam proses pembongkaran muatan perusahaan pelayaran selaku agen bekerja sama dengan Perusahaan Bongkar Muat (PBM) PT. Kuala Jaya Samudera dan PT. Duet Pratama Samudera, sewaktu membongkar muatan perusahaan bongkar muat akan menghitung/ mencatat beberapa muatan yang dapat dibongkar dalam satu hari dan di catat dalam Daily Report.

Daily report adalah dokumen pemuatan barang yang menyatakan laporan kerja harian pada saat barang dibongkar atau dimuat pada masingmasing palka, setelah perusahaan bongkar muat mencatat ke daily report maka perusahaan bongkar muat akan mem-berikan daily report, ke perusahaan pelayaran selaku agen, kemudian agen akan mencatat dokumen itu ke Time Sheet gunanya untuk pem-beritahuan ke principal atau pemilik kapal melalui email.

Time Sheet adalah dokumen pemuatan barang yang berisi-kan keadaan kapal pada waktu pemuatan dengan mencantumkan hari kerja, alat kerja, jam kerja, waktu kerja dihitung per jam. Segala sesua-tu yang terjadi ketika proses pembongkaran seperti hujan, Crane kapal atau Crane darat rusak, alat pengangkut truck tidak ada. Semua itu akan disampaikan kepada principal atau pemilik kapal melalui Email oleh perusahaan pelayaran (Agen).

\section{d.Sebelum Kapal Berangkat}

Setelah kapal selesai melakukan pemuatan didermaga, maka agen selaku perwakilan dan pemilik kapal harus mengurus segala keperluan kapalnya sebelum berangkat kepelabuhan tujuan (next port), seperti pemberitahuan kepada pihak instansi yang terkait, pengurusan dokumen dan keperluan kapal selama berlayar.

Instansi yang terkait dalam proses untuk Clearance Out dan dokumen yang di persiapkan untuk keberangkatan kapal :

\section{1). Karantina Kesehatan}

Untuk mengambil kembali buku kesehatan kapal (Health Book) yang telah diperiksa oleh karantina dan mendapatkan surat persetujuan berlayar dari karantina.
Untuk mengambil kembali passport Nakhoda dan Awak kapal yang warga Negera Asing yang telah di stempel/ di cap oleh pihak Imigrasi.

\section{3). PT. Inalum}

Memberikan surat pemberitahuan dari agen ke perusahaan PT. In-alum bahwa kapal yang telah selesai bongkar dan yang telah selesai sandar di dermaga akan melaksanakan pelayaran selanjut-nya.

4). Kantor Syahbandar dan Otoritas Pelabuhan (KSOP)

a).Instansi yang memberikan surat persetujuan berlayar sesuai permohonan agen.

Pihak perusahaan pelayaran (Agen) mengajukan permohonan surat izin berlayar ( Clearance Out), adapun dokumen yang ha-rus dibawa yaitu :

(1).Master Sailing

Surat pernyataan dari Nahkoda

(2).Manifest

Jumlah muatan/ penumpang

(3).Crew List

Daftar Nakhoda dan ank buah kapal

(4).Tanda bukti kwitansi Penerimaan Negara

Bukan Pajak (PNBP),

Pembayaran uang Rambu, pembayaran uang Navigasi, dan pembayaran untuk radio pantai. Setelah semua dokumen dipersiapkan, selanjutnya diserahkan ke Kantor Syahban-dar dan Otoritas Pelabuhan (KSOP) Kemudian pihak Kan-tor Syahbandar dan Otoritas Pelabuhan menerbitkan Surat Persetujuan Berlayar (Port Clearance).

b).Dokumen yang di persiapkan sebelum keberangkatan kapal :

\section{1).Departure Condition}

Adalah laporan dibuat Nakhoda tentang kondisi kapal terdiri dari Draf depan dan belakang, persediaan di kapal antara lain ; Bunker, Fresh Water (FW), Oil dan Departure Condition tersebut diteruskan kepada owner`s

\section{2). Imigrasi}




\section{2).Ijin Olah Gerak}

Adalah Ijin yang dikeluarkan Syahbandar agar kapal dapat melakukan gerakan dari satu tempat ke tempat lain, da-lam/keluar pelabuhan.

\section{3).Notice Of Readiness (NOR)}

Suatu surat yang dibuat oleh Nakhoda yang menyatakan bahwa kapal telah siap untuk melaksanakan pembongkaran atau pemuatan.

\section{4).Passport (untuk ABK Asing)}

Adalah dokumen resmi yang dikeluarkan oleh pejabat yang berwenang dari suatu Negara yang membuat identi-tas pemegangnya dan berlaku untuk melakukan perjalanan antara Negara.

\section{5).Original Dokumen Kapal}

Adalah dokumen kapal yang diturunkan untuk diperik-sanya masa berlaku dokumen oleh pihak KSOP. Setelah pemeriksa selesai, pihak agen mengambil lagi original dokumen ke kantor syahbandar dan langsung diserahkan kembali ke Nakhoda kapal.

\section{6).Time Sheet}

Adalah dokumen pemuatan barang yang berisikan keadaan kapal pada waktu pemuatan barang dengan mencantumkan hari kerja, cuaca, dan waktu kerja dihitung per jam.

\section{7).Outward Manifest}

Adalah manifest untuk keberangkatan yang menyatakan bahwa kapal tersebut berangkat membawa jumlah muatan ataupun dalam keadaan Nil Cargo.

\section{8).Tugboat Usage Unberthing}

Adalah untuk membantu proses pengeluaran kapal dari dermaga ke ambang luar dengan menggunakan tunda. Dan dokumen - dokumen ini harus diketahui oleh Nakhoda dan di tanda tangani oleh nakhoda.

\section{e.Setelah Kapal Berangkat}

Setelah kapal meninggalkan pelabuhan, perusahaan pe-layaran (agen) membuat perhitungan mengenai pembayaran atau jasa keagenan dan segala pembayaran lain selama kapal berada di pelabuhan. Kemudian biaya-biaya tersebut kepada General Agent atau Owner`s (pemilik kapal) dengan perjanjian.

Biaya-biaya operasional yang berkaitan dengan pelayanan kapal selama berada di pelabuhan merupakan bagian dari biaya disbursement yaitu seluruh biaya-biaya operasional selama kapal di pelabuhan, antara lain :

1). Biaya yang berkaitan dengan yang melayani kebutuhan kapal di dermaga, seperti, bunker, penyediaan bahan makanan dan kebutuhan lainnya.

2). Biaya yang berkaitan dengan ship husbanding, seperti : biaya-biaya clearence termasuk terkait mempengaruhi surat/ doku-men-dokumen kapal yang telah habis masa berlakunya.

3). Biaya-biaya yang berkaitan dengan menyiapkan tempat tam-bat/ sandar, pemanduan kapal didermaga. Keterangan :

\section{1)Biaya Labuh}

Biaya yang dikeluarkan port agent yang atas persetujuan oleh general agent berdasarkan hasil floating, maka di ketahuilah letak rencana penyandaran kapal-kapal di pelabuhan.

\section{2).Biaya Tambat}

Biaya penggunaan tambat (dermaga) atau jasa tambat yang di bayar ke. PT. Pelindo I Cabang Kuala Tanjung untuk bisa ka-pal tambat di dermaga.

\section{3).Biaya Pandu}

Biaya jasa pemanduan yaitu pandu dan tunda.

4).Biaya Sarana Bantu Navigasi Pelayanan (SNBP)

Biaya ini dibayar melalui Administrator pelabuhan Kuala Tanjung.

5).Biaya Air Tawar

Untuk memenuhi keperluan/ permintaan kapal.

6). Biaya lainnya. Jenis biaya lainnya, antara lain terdiri dari :
a).Team Cheking ke atas kapal
b).Clearance passport / Crew List
c).Perpanjangan sertifikat
d).Sijil on \& sijil off crew
f).Instansi-Instansi yang Terkait.

Instansi yang terkait yaitu :
1).Karantina Kesehatan
2).Bea dan Cukai
3).Kantor Syahbandar Otoritas Pelabuhan (KSOP) 


\section{4).PT. Pelindo I Cabang Kuala Tanjung}

a).Instansi yang terkait dalam Clearance In yaitu :

(1).Kesehatan Pelabuhan (KESPEL)

Instansi ini bertugas memeriksa keadaan kapal dan awak kapal, untuk memastikan kapal dan awak kapal tersebut tidak membawa penyakit di pelabuhan tersebut.

Agen melaksanakan Clearance buku kessehatan (Health Book) mengeluarkan Sertifikat Kesehaatan (Helath of Declaration) dari Dinas Kesehatan Pelabuhan (KESPEL) yang menyatakan bahwa kapal dan awak kapal tersebut bebas dari hama dan penyakit yang menular dan berbahaya.

\section{(2).Imigrasi Pos Kuala Tanjung}

Instansi ini bertugas untuk memeriksa dan mengesahkan Passport (Seaman Book) pada saat kapal datang dan kapal akan berangkat. Setelah semua instansi selesai melakukan tugas mas-ingmasing sewaktu di atas kapal maka selanjutnya agen harus mengambil dokumen dan sertifikat

kapal lainnya yang diperlukan untuk melakukan Clearnce In di beberapa instansi terkait, anatara lain :

Agen mengurus Clearance in Passport awak kapal untuk dicap dan disahkan dengan melampirkan daftar awak kapal (Crew List).

(3). Kantor Pelayanan Bea dan Cukai.

Instansi ini bertugas memeriksa keadaan muatan kapal, petugas Direktorat Jendaral Bea dan Cukai naik keatas kapal apabila kapal tersebut datang membawa muatan untuk dibongkar dan kembali ke kapal setelah selesai pemuatan.

Agen memberikan manifest dan apabila kapal tersebut da-tang tanpa muatan, maka manifest tersebut dinamakan Nil Car-go.

(4).Kantor Syahbandar dan Otoritas Pelabuhan (KSOP) Kelas V Kuala Tanjung.

Agen melaksanakan Clearance In dokumen dan sertifikat kapal ke Kantor Syahbandar dan Otoritas Pelabuhan (KSOP) pa-da bagian Kelaiklautan kapal dan bidang penjagaan dan Keselamatan.

\section{g).Dokumen Pendukung}

1).Dokumen/ Sertifikat Kapal

a).Surat Tanda Kebangsaaan (Certificate of Registy)

b).Surat Ukur (International tonnage certificate)
c).Sartifikat Garis Muat (International load line certificate)

d).Daftar Anak Buah Kapal (Crew List)

e).Sertifikat Keamanan Radio kapal barang (Cargo

Ship Safety Radio Certificate)

f).Sertifikat Keamanan (International Ship Security

Certificate)

g).Surat Persetujuan Terakhir (Last Port Clearance)

h).Sertifikat Perlengkapan Kapal Barang (Cargo Ship Safety Equipment Certificate)

i).Sertifikat Keselamatan Bangunan (Safety

Constraction Certifi-cate).

2).Dokumen Muatan
a). Shipping Order $(\mathrm{S} / \mathrm{O})$
b). Shipping Instruction
c). Mate Receipt
d). Tally Sheet
e). Manifest
f). Bill Of Lading (B/L)
g). Latter Of Indemnity
h). Stowage Plan
i). Statement Of Fact
j). Notice Of Readiness
k). Discharging List

3)..Dokumen Crew
a). Sertifikat Keahlian Pelaut ( ANT/ ATT )
b). Buku Pelaut
c).Sijil Awak Kapal/ Crew List
d). Perjanjian Kerja Laut
e). Sertifikat Kesehatan Crew
f). Paspor (untuk ABK asing)
g). Radar Simulator
h).Operator Radio Umum (ORU)
i) Survival Craft and Resque Boats (SCRB)
j). Medical Care (MC) 


\section{k). ARPA Simulator (AS)}

\section{4).Dokumen Terkait}

\section{a).Departure Condition}

Adalah laporan dibuat Nakhoda tentang kondisi kapal terdiri dari Draf depan dan belakang, persediaan di kapal antara lain; Bunker, Fresh Water (FW), Oil. dan Departure Condition terse-but diteruskan kepada owner`s

\section{b). Ijin Olah Gerak}

Adalah Ijin yang dikeluarkan Syahbandar agar kapal dapat melakukan gerakan dari satu tempat ke tempat lain, dalam/keluar pelabuhan.

\section{c). Passport (untuk ABK Asing)}

Adalah dokumen resmi yang dikeluarkan oleh pejabat yang ber-wenang dari suatu Negara yang membuat identitas pemegangnya dan berlaku untuk melakukan perjalanan antara Negara.

\section{d).Original Dokumen Kapal}

Adalah dokumen kapal yang diturunkan untuk diperiksanya masa berlaku dokumen oleh pihak KSOP. Setelah pemeriksa selesai, pihak agen mengambil lagi original dokumen ke kantor syahbandar dan langsung diserahkan kembali ke Nakhoda ka-pal.

e).Time Sheet

Adalah dokumen yang mencantumkan tentang kegiatan bongkar/muat kapal berisikan jam kerja, stop kerja, serta ket-erangan yang menyebabkan kegiatan terhenti.

\section{f). Outward Manifest}

Adalah manifest untuk keberangkatan yang menyatakan bah-wa kapal tersebut berangkat membawa jumlah muatan ataupun dalam keadaan Nil Cargo. 


\section{KESIMPULAN}

Setelah penulis makalah ini membahas tentang keagenan dalam menangani doku-men dan kebutuhan kapal , maka penulis menyimpulkan.

Aktifitas keagenan dalam menangani dokumen dan kebutuhan kapal di PT. Gesuri Lloyd Cabang Kuala Tanjung ialah:

Pengawasan mulai dari masuk dan keluarnya kapal di pelabuhan Kuala Tanjung. Mulai dari mempersiapkan dokumen dan memberikan fasilitas yang di-perlukan dalam pelayanan penyandaran pengawasan kapal, maka harus dilengkapi dengan peralatan dan sarana yang sesuai dengan penggunaannya yaitu radio panggil/ telepon, pelampung, helm pelindung kepala. Pengurusan dokumen kapal mengawasi proses penyandaran didermaga, mengecek kegiatan proses bongkar muat kapal di dermaga dan sammpai kapal tersebut akan berlayar menuju pelabuhan berikutnya (Next Port).

\section{DAFTAR PUSTAKA}

Engkos Kosasih, Manajemen Perusahaan Pelayaran, Jakarta: Raja Grafindo Persada,2009

Lasse, D. A. Keselamatan Pelayaran . Jakarta: Rajawali Pers, 2014

Triadmodjo, Bambang. Perencanaan Pelabuhan. Jakarta: Beta Offset, 2010

Undang- undang Republik Indonesia Nomor 17 Tahun 2008, Tentang Pelayaran 